\title{
Perceived information provision and information needs in adolescent and young adult
}

cancer survivors

Salome Christen $\mathrm{MA}^{1, *}$, Esther Weishaupt MA ${ }^{1, *}$, Janine Vetsch $\mathrm{PhD}^{1,2,3}$, Corina S. Rueegg $\mathrm{PhD}^{1,4}$, Luzius Mader $\mathrm{PhD}^{1}$, Silvia Dehler MD, $\mathrm{MPH}^{5,6,7}$, Gisela Michel $\mathrm{PhD}^{1,8}$

*These two authors contributed equally to the publication.

${ }^{1}$ Department of Health Sciences and Health Policy, University of Lucerne, Switzerland

${ }^{2}$ Discipline of Paediatrics, School of Women's and Children’s Health, UNSW Medicine,

University of New South Wales, Australia

${ }^{3}$ Kids Cancer Centre, Sydney Children’s Hospital, Australia

${ }^{4}$ Oslo Centre for Biostatistics and Epidemiology, Oslo University Hospital and Institute of

Basic Medical Sciences, University of Oslo, Norway

${ }^{5}$ Departement Gesundheit und Soziales, Abteilung Gesundheit, Aarau, Switzerland

${ }^{6}$ Cancer Registry Zurich and Zug, Institute of Surgical Pathology, University Hospital

Zurich, Switzerland

${ }^{7}$ Epidemiology, Biostatistics and Prevention Institute, University Zurich, Switzerland

${ }^{8}$ Institute of Social and Preventive Medicine, University of Bern, Switzerland

\section{Corresponding author:}

Gisela Michel, Department of Health Sciences and Health Policy, University of Lucerne Frohburgstrasse 3, 6002 Lucerne, Switzerland

Ph:+41 41 2295955, Fax: +41 41 2295635, E-mail: gisela.michel@unilu.ch

\section{Funding:}

This work was supported by the Swiss National Science Foundation (Ambizione grant PZ00P3_121682/1 and PZ00P3-141722 to GM; Grant 100019_153268 / 1). CSR has received funding from the European Union Seventh Framework Programme (FP7-PEOPLE2013-COFUND) under grant agreement $n^{\circ} 609020$ - Scientia Fellows.

This version of the manuscript was submitted to the European Journal of Cancer Care on November 28th 2017. 


\section{ABSTRACT}

Knowledge on former diagnosis, treatment and survivorship is important for adolescent and young adult cancer survivors (AYACS) to make informed health care decisions. We aimed to 1) describe the information AYACS reported to have received, 2) identify current information needs and survivors' preferred format of communication, and 3) examine associations between information needs and cancer-related/socio-demographic characteristics, psychological distress and health-related quality of life (HRQoL). We identified AYACS (16-25 years at diagnosis; $\geq 5$ years since diagnosis) through the Cancer Registry Zurich and Zug. Survivors received a questionnaire on information received and current IN, socio-demographic information, psychological distress (Brief Symptom Inventory-18) and HRQoL (SF-12). Clinical characteristics were available from the cancer registry. We used descriptive statistics and univariable regression models. Of 160 responders, most reported to have received information on disease (96.3\%), treatment (96.3\%), and follow-up (89.4\%), fewer on late effects (63.1\%). Survivors reported information needs on late effects (78.7\%), follow-up (71.3\%), disease (58.1\%) and treatment (55.6\%). Information needs were associated with experiencing psychological distress and lower mental HRQoL. Most Swiss AYACS have information needs, especially on follow-up and late effects. Therefore, AYACS should be personally, continuously and proactively informed about their disease, treatment, follow-up care and late effects.

Key words: Adolescent and young adult cancer survivors; information needs; information provision; cancer registry; Europe; questionnaire survey 


\section{INTRODUCTION}

Adolescent and young adult (AYA) cancer patients and survivors form a distinct group with special needs that fall between the paediatric and adult care (Adolescent and Young Adult Oncology Progress Review Group, 2006; Olsson, Jarfelt, Pergert, \& Enskar, 2015; Palmer, Mitchell, Thompson, \& Sexton, 2007). They are facing unique physical, emotional and social challenges due to their age and developmental life stage (Adolescent and Young Adult Oncology Progress Review Group, 2006; Albritton \& Bleyer, 2003; Mader et al., 2017). Although survival of AYA cancers has improved significantly in the past decades, reaching nowadays 87\% (Gatta et al., 2009), survivors are at risk for late effects such as neoplasms, cardiovascular diseases or poor mental health (Oeffinger et al., 2006; Rugbjerg \& Olsen, 2016; Tai et al., 2012; Zhang et al., 2014). Therefore, continued follow-up care is recommended for survivors of childhood and AYA cancers (Hewitt, Greenfield, \& Stovall, 2006; Oeffinger, Eshelman, Tomlinson, Buchanan, \& Foster, 2000; Zhang et al., 2014). In Switzerland, to date there is no standardized follow-up care for survivors and procedures depend on the treating clinic and paediatric oncologist (Meier et al., 2017). A study in AYACS in Switzerland showed that 57.5\% reported still attending follow-up care after a mean time of almost 12 years since diagnosis (Christen et al., 2016).

AYA cancer survivors (AYACS) expressed that adequate information regarding survivorship was important for them to make health care decisions (Wong et al., 2017). However, many AYACS reported a need for more information regarding their disease, treatment and late effects (DeRouen et al., 2015; Keegan et al., 2012; Shay, Parsons, \& Vernon, 2017; Zebrack, 2009). A patient information need can be defined as "recognition that their knowledge is inadequate to satisfy a goal, within the context/situation that they find themselves at a specific point in the time” (Ormandy, 2011). In Switzerland, 80\% of childhood cancer survivors (CCS) and 70\% of parents of CCS reported to have information needs on late 
effects (Gianinazzi et al., 2014; Vetsch et al., 2015). Additionally, more than 12 years after diagnosis, over $60 \%$ of CCS expressed information needs regarding their disease, treatment and follow-up (Gianinazzi et al., 2014). Swiss AYACS rated “information on potential late effects” as an important aspect of a follow-up consultation (Christen et al., 2016). It has also been shown that survivors who were satisfied with their state of knowledge, had better health-related quality of life (HRQoL) (DeRouen et al., 2015; Husson, Mols, \& van de Poll-Franse, 2011), and lower levels of depression and anxiety (Husson et al., 2011). To provide patient-centred care, it is pivotal to identify and meet patients' information needs (Lie, 2017; Ormandy, 2011). At the same time it should be taken into account that information needs differ across age groups, cultural background, educational levels and coping styles (Husson et al., 2011). To date, little is known about AYACS' information needs and their perception of information provision. In the present study we therefore aimed to 1) describe the information Swiss AYACS reported to have received from a health professional, 2) identify current information needs and preferred format of communication, and 3) examine the association of information needs with cancer-related and socio-demographic characteristics, psychological distress and HRQoL.

\section{METHODS}

\section{Sample and procedure}

For this cohort study, we identified AYACS through the Cancer Registry Zurich and Zug (Switzerland). Survivors were eligible if they had been diagnosed with cancer between January 1990 and December 2005, aged 16-25 years at diagnosis and survived $\geq 5$ years after diagnosis. To allow direct comparison with paediatric patients of the related Swiss Childhood Cancer Survivor Study,(Kuehni et al., 2012), we restricted the sample to the following 
diagnoses: leukaemia, germ cell tumour, lymphoma, central nervous system (CNS) tumour, neuroblastoma, renal, hepatic and bone tumour, and soft tissue sarcoma.

Participants' addresses were available from the Cancer Registry Zurich and Zug, and we updated them by web search and by contacting the community of last residence. We pilot tested the questionnaire with 30 randomly selected AYACS. We sent eligible survivors a cover letter, the study information, an informed consent sheet, the questionnaire and a prepaid return envelope. After 4 weeks, we sent non-responders a reminder letter and the same questionnaire. We sent the questionnaires between August 2010 and January 2012. The Cantonal Ethics Committee of Zurich provided ethical approval and all participants provided informed consent.

\section{Measurements}

The questionnaire included questions about follow-up care, perceived information provision and information needs, socio-demographic characteristics, clinical characteristics, HRQoL and psychological distress.

\section{Perceived information provision}

Survivors were asked whether they remembered ever having received information from a medical doctor or health professional about the original disease, treatment of the original disease, follow-up, late effects and other information. For each topic, they could indicate whether they had ever received oral information, written information or no information. Survivors not remembering having received information on a topic could indicate whether they would have liked to have received this information after the treatment on a 3-point Likert scale (very important/important/unimportant). 


\section{Information needs}

We asked survivors whether they currently had information needs on their original disease, treatment of the original disease, follow-up, late effects, or other information. They could specify their preferred format of information communication (oral information by their doctor, general written information, personal written information, general information online, other format of communication; multiple answers were possible), or that they had no information needs.

\section{Socio-demographic and clinical characteristics assessed by questionnaire}

We assessed survivors’ age, sex, educational achievement (primary education: compulsory schooling only; secondary education: vocational training or high school degree; tertiary education: college or university degree) (Kuehni et al., 2012), partnership (if they currently had a partner or were married: yes/no), and migration background (survivors were classified as having a migration background if they were not Swiss citizens since birth or were not born in Switzerland). We asked survivors whether they had had a cancer relapse (yes/no) and whether they suffered from any serious late effects (yes/no).

\section{Health-related Quality of Life (HRQoL)}

HRQoL was assessed using the 12-Item Short-Form Health Survey (SF-12) (Ware, Kosinski, \& Keller, 1996). The SF-12 provides two summary scores: the physical component summary (PCS) and the mental component summary (MCS). We constructed the PCS and MCS using norms from the German Socio-Economic Panel (SOEP) (Andersen, Mühlbacher, Nübling, Schupp, \& Wagner, 2007). The PCS and MCS scores were standardized into T-scores (mean=50, SD=10), with higher scores indicating higher HRQoL. 


\section{Psychological distress}

We used the Brief Symptom Inventory-18 (BSI-18) to identify symptoms of psychological distress (Derogatis, 2000). The German translation showed good psychometric qualities (Franke et al., 2017; Spitzer et al., 2011). The BSI-18 assesses three dimensions: somatization, depression and anxiety (6 items each), and a Global Severity Index (GSI; all 18 items). Participants were asked to report how much they were disturbed by symptoms in the past 7 days. They rated all items on a 5 -point Likert scale ( $1=$ not at all to $5=$ strongly). To identify psychological distress among individuals, sum raw scores were T-standardized (mean=50, SD=10) (Derogatis, 2000). As suggested by Zabora et al., and as previously done in a study of Swiss CCS, participants with a T-Score $\geq 57$ were defined as distressed (Gianinazzi et al., 2013; Zabora et al., 2001).

\section{Clinical information from the Cancer Registry Zurich and Zug}

We received medical information on diagnosis, treatment, age at diagnosis and time since diagnosis from the cancer registry. We classified diagnosis according to the International Classification of Childhood Cancer-3rd Edition (Steliarova-Foucher, Stiller, Lacour, \& Kaatsch, 2005). For the analyses, diagnoses were grouped into four categories: leukaemia/lymphoma, CNS tumour, germ cell tumour and other tumours. Treatment was hierarchically coded as surgery only, chemotherapy (may have had surgery, but not radiotherapy) or radiotherapy (may have had surgery and/or chemotherapy).

\section{Statistical analysis}

We conducted all analyses using STATA 14.0 (StataCorp LP, College Station, TX). We compared participants and non-participants of the study with descriptive statistics, chi-square tests and t-tests. For aim 1, we used descriptive statistics. We generated four new variables for each topic (disease, treatment, follow-up, late effects), which reflected survivors’ 
perception of information provision in the respective topics (ever received information (written or oral): yes/no). We also generated an overall variable indicating the format by which the information was provided (oral, written, oral \& written, no information). For aim 2, we generated an overall variable that indicated any current information need (yes/no), and used descriptive statistics to describe current information needs and preferred format of communication. We used descriptive statistics and chi-square tests to compare the format of information provision with having an information need. For aim 3, we used univariable logistic regression models to analyse associations of cancer-related and socio-demographic characteristics, psychological distress, and HRQoL with current information needs.

\section{RESULTS}

\section{Study population}

Of 469 eligible survivors, we traced and contacted 389 (Supplemental Fig. 1). Of those, 160 (41.1\%) returned the questionnaire. Participants' mean age at study was 34.0 years (SD=5.8; range 20-46 years), mean age at diagnosis was 21.6 years (SD 2.9; range 16-25 years) and mean time since diagnosis was 12.4 years ( $S D=4.8$; range 5-21 years; Table 1). Most participants had been diagnosed with leukaemia/lymphoma ( $n=73,45.6 \%)$ or germ cell tumours (n=46, 28.7\%). Socio-demographic and clinical characteristics did not differ between participating and non-participating survivors (Table 1).

\section{Aim 1: Perceived information provision}

Most of the survivors reported to have received information on disease ( $n=154,96.3 \%)$, treatment ( $n=154,96.3 \%)$ and follow-up ( $n=143,89.4 \%)$ (Fig. 1). Of the survivors who reported not to have received information, the majority rated the importance of receiving information as "very important” or “rather important” (disease $n=4,66.7 \%$; treatment $n=4$, 66.7\%; follow-up n=14, 82.4\%). Many survivors did not remember ever having received 
information on late effects ( $n=59,36.9 \%)$ (Fig. 1). Most of these 59 survivors rated the importance of receiving information about late effects as “very important" or "rather important” (n=48; 81.4\%). Two survivors (1.3\%) reported not having received any information at all.

Overall, most survivors reported having received oral information $(n=83,51.9 \%)$ or oral and written information ( $\mathrm{n}=73,45.6 \%)$. Two survivors reported having received written information only (1.3\%).

\section{Aim 2: Current information needs \& preferred format of information communication}

Overall, more than half of survivors reported to have information needs on disease ( $n=93$, $58.1 \%)$ and treatment $(\mathrm{n}=89,55.6 \%)$ and around three quarter reported information needs on follow-up (n=114, 71.3\%) and late effects (n=126, 78.7\%; Fig. 2). Across all topics, 26 survivors (16.3\%) reported to have no information needs at all. Besides two exceptions (no information received on treatment; only written information received on late effects), survivors who reported to have received written and oral information were the ones with least information needs for all topics (disease $\mathrm{p}=0.500$; treatment $\mathrm{p}=0.388$; follow-up $\mathrm{p}=0.222$; late effects $p=0.251$ ) (Fig. 3). For each topic, the preferred format was oral information from the doctor (disease: 48\%; treatment: 49\%; follow-up: 45\%; and, late effects: 47\%) followed by personal written information (disease: 39\%; treatment: 39\%; follow-up: 32\%; and, late

effects: 40\%; Fig. 4). General online information was the least preferred format (disease: 26\%; treatment: 21\%; follow-up: 23\%; and, late effects: 23\%).

\section{Aim 3: Associations with information needs}

No socio-demographic or clinical characteristics were associated with information needs. In univariable logistic regression models, significantly more survivors with psychological distress (BSI $\geq 57$ ) reported information needs on disease (OR=2.50; 95\%CI:1.08-5.77; 
p=0.025). Similarly, survivors with higher MCS (higher mental HRQoL) reported fewer information needs on disease $(\mathrm{OR}=0.96$; 95\%CI:0.92-0.99; $\mathrm{p}=0.006)$ and treatment (OR=0.97; 95\%CI:0.94-1.00; $\mathrm{p}=0.041$; Table 2).

\section{DISCUSSION}

The majority of Swiss AYACS reported having received information on disease, treatment and follow-up, but many did not remember receiving information on late effects. More than $80 \%$ of survivors reported to have current information needs. Survivors' preferred format of information provision was oral information from the doctor or personal written information. Having information needs were associated with experiencing psychological distress and lower mental HRQoL.

We can assume that all Swiss AYACS or their parents received specific information about their disease, treatment, follow-up recommendations and possible late effects by a health care professional. However, similar to studies in CCS (Gianinazzi et al., 2014; Lie et al., 2015), more than one third of survivors reported never having received information on late effects. This might have several reasons: in younger AYA cancer patients, comprehensive information about their disease and treatment is often provided to parents (Palmer et al., 2007), and younger AYACS may not have been provided with all the information personally. However, survivors themselves expressed the wish to be offered comprehensive information (Palmer et al., 2007). Additionally, it has been shown with increasing amounts of information presented to the patient, the proportion of correctly recalled information is getting smaller (McGuire, 1996). Additionally, the memory for medical information is affected by the perceived importance of the information (Kessels, 2003). At the time of diagnosis and treatment, a huge amount of information is presented to patients and their families, and the 
importance of information on late effects might be perceived as low - as the focus lies on surviving the cancer. Patients and their families might focus on disease- and treatment-related information and it might seem less important to memorize information on follow-up and late effects. Survivors themselves further wished that information were continuously available (Lie et al., 2015). Survivorship and late effects, as well as the provision of information have become an important part in the care of AYACS in the last decade. This might result in lower information needs in only recently diagnosed AYACS. Overall, information on follow-up and late effects should be provided at different points of the cancer trajectory, particularly at the end of treatment and during follow-up consultations, when survivors have the capacity to focus on this information.

Four studies have previously addressed information needs in AYACS (DeRouen et al., 2015; Keegan et al., 2012; Shay et al., 2017; Zebrack, 2009). Two North American studies found that more than half of survivors reported a need for information about their disease, treatment, cancer recurrence and late effects (DeRouen et al., 2015; Shay et al., 2017), and one found that $78 \%$ of survivors reported a need for information about late effects (Shay et al., 2017), which is in line with our results. Zebrack (2009) found that being unmarried, unemployed, not being a college graduate, younger at diagnosis, having more health problems and a poorer health status were associated with reporting unmet information needs about cancer. Keegan et al. (2012) found that males were generally more likely to report unmet information needs, older age at study was associated with unmet needs related to treatment, late effects and cancer recurrence, and a poor health status was associated with unmet needs related to late effects and getting a new cancer. In contrast to this, we found no associations between information needs and sex, level of education, partnership, migration background, and clinical characteristics. This is reassuring, as it indicates that among Swiss 
AYACS and regarding socio-demographic and clinical characteristics, there is no specific subgroup at risk for unmet information needs.

In our study, more than $70 \%$ of survivors reported current information needs on follow-up and late effects, and more than half of survivors reported current information needs on disease and treatment. This is similar to the information needs in Swiss CCS and in parents of Swiss CCS (Gianinazzi et al., 2014; Vetsch et al., 2015). Although it is known that information needs vary across the cancer trajectory (Fletcher, Flight, Chapman, Fennell, \& Wilson, 2017), this is a remarkable proportion of survivors with information needs. Partly, this may have methodological reasons. Survivors might not have felt a need for information before being prompted by the questions on information needs in our questionnaire. However, even if our questionnaire made participants aware of information needs, these needs are real and have to be taken seriously. In AYACS, it has been shown that survivors who received a written treatment summary were less likely to report information needs (Shay et al., 2017). Offering information pro-actively, which has been desired by CCS (Lie et al., 2015), may contribute to satisfy information needs (Lie, 2017). Also, among young adult cancer survivors, a survivorship care plan was associated with higher confidence in managing their survivorship care (Casillas et al., 2011). In Switzerland, it is planned to provide all CCS and AYACS with a survivorship passport (Lack, 2016; Poplack et al., 2014). This passport will contain comprehensive information on survivor's cancer diagnosis and treatment, and individual recommendations for follow-up care (Lack, 2016). Our study and a previous study (Gianinazzi et al., 2014) have shown that survivors value personalized information. The survivorship passport complies with this preference. It will contribute to improving survivors’ knowledge about their diagnosis and treatment, fulfil basic information needs on disease, treatment, follow-up care and late effects and empower the survivors to manage their own 
follow-up care. Additionally, for Swiss AYACS who currently attend regular or irregular follow-up (Christen et al., 2016), follow-up consultations provide an opportunity for survivors and health-care professionals to meet survivors' information needs.

In our study, survivors reporting information needs had higher psychological distress and lower mental HRQoL. This is similar to other studies, which found that fulfilled information needs were associated with higher HRQoL (DeRouen et al., 2015; Husson et al., 2011) and lower levels of depression and anxiety (Husson et al., 2011).

A previous study in Swiss CCS found that their preferred format of information provision was written personal information, followed by oral information (Gianinazzi et al., 2014). This is in line with our results, as both groups of survivors seem to favour personalized information. In contrast, a study from the UK examining health behaviour information needs and preferences of AYACS found that survivors preferred online information, apps or short leaflets about health behaviour (Pugh, Hough, Gravestock, Jackson, \& Fisher, 2017).

Although Swiss AYACS value personalized information highly, oral advice only is not very successful, and should be complemented with written information (Kessels, 2003). Similarly, we found that survivors who reported to have received oral and written information were less likely to have information needs than those who reported to have received oral information only.

A systematic review found that it is common for AYACS to access online health information (Sansom-Daly et al., 2016), although some AYACS reported to specifically avoid the internet (Lin, Sansom-Daly, Wakefield, McGill, \& Cohn, 2017). Online information was the least preferred format of communication in our study. However, a reason for this might be that 
$90 \%$ of the participants of our study were born before 1985 and, therefore, most of them are not digital natives. It is possible that survivors born after that time have a higher preference for online information, as for them the internet and digital media are omnipresent. It was suggested that a website with specific and age-appropriate information can be a valuable resource to improve survivors’ knowledge (Knijnenburg et al., 2013). Recently, an online platform (www.kinderkrebs-schweiz.ch) with general information about childhood and adolescent cancer, follow-up and late effects has been set up for Swiss childhood and AYACS. Due to the inclusion of paediatric oncology experts in the development of the content, survivors might trust this platform more than other online information; Survivors even have the possibility to ask specific questions regarding their disease, treatment, followup or late effects online. CCS have suggested an interactive website to be important for information provision (Lie et al., 2015), and AYACS may value the personal aspect of an interactive website. In addition to the personal contact with the doctor or other healthcare professionals during follow-up care consultations, this platform might help to meet survivors' information needs.

A limitation of this study is the relatively low response rate (41.1\%), which has been a challenge in other studies of AYACS (Harlan et al., 2011). A relatively large number of AYACS could not be traced in our study (17.1\%). A reason for this might be that the AYACS population is very mobile. Therefore, they are difficult to reach for research and to be tracked for follow-up care (Tonorezos \& Oeffinger, 2011). Although participants and nonparticipants were comparable, non-participants may have other information needs and preferences. Moreover, a qualitative approach could provide more in-depth insights into AYACS information needs. The cross-sectional study design further precludes establishing causal inferences. Another limitation is that only basic medical information was available 
through the Cancer Registry Zurich and Zug, so we had to rely on the survivors' self-reported information on late effects and relapse.

A major strength of this study is the population-based sample of AYACS for a large region in Switzerland (Canton of Zurich). Another strength is the self-reported information about perception of information provision and current information needs. We were interested to see what information survivors remembered to have received and were able to gain an understanding of the survivors’ current information needs.

Swiss AYA cancer survivors have a need for more information especially on follow-up and possible late effects, and prefer personalized information orally from their doctor or personalized written information. In Switzerland, the survivorship passport and the platform “Childhood Cancer Switzerland” are initiatives that may help meeting survivors’ needs. In addition to this, despite being young, AYACS should be personally, continuously and proactively informed about their disease, treatment, follow-up care and late effects.

\section{CONFLICT OF INTEREST STATEMENT}

No conflict of interest for any of the authors.

\section{ACKNOWLEDGMENTS}

We thank all survivors for participating in our survey and the members of the study team (Philip Laeuppi, Anna Hohn, Zina Heg-Bachar). This article is based on a revised version of the master thesis "Information needs in adolescent and young adult cancer survivors" that has been submitted to the Faculty of Humanities and Social Sciences at the University of Lucerne in 2015. The master thesis has been prepared by Esther Weishaupt under the supervision of Gisela Michel and Corina S. Rueegg. 


\section{REFERENCES}

Adolescent and Young Adult Oncology Progress Review Group. (2006). Closing the Gap: Research and Care Imperatives for Adolescents and Young Adults with Cancer. Retrieved from Bethesda, MD: http://planning.cancer.gov/library/AYAO PRG Report 2006 FINAL.pdf

Albritton, K., \& Bleyer, W. A. (2003). The management of cancer in the older adolescent. EurJ Cancer, 39(18), 2584-2599.

Andersen, H. H., Mühlbacher, A., Nübling, M., Schupp, J., \& Wagner, G. (2007). Computation of Standard Values for Physical and Mental Health Scale Scores Using the SOEP Version of SF-12v2. Schmollers Jahrbuch, 127, 171-182.

Casillas, J., Syrjala, K. L., Ganz, P. A., Hammond, E., Marcus, A. C., Moss, K. M., ... Friedman, D. L. (2011). How confident are young adult cancer survivors in managing their survivorship care? A report from the LIVESTRONG Survivorship Center of Excellence Network. J Cancer Surviv, 5(4), 371-381. doi:10.1007/s11764-011-0199-1

Christen, S., Vetsch, J., Mader, L., Dehler, S., Korol, D., Kuehni, C., . . Michel, G. (2016). Preferences for the organization of long-term follow-up in adolescent and young adult cancer survivors. Support Care Cancer, 24(8), 3425-3436. doi:10.1007/s00520-016-3157-7

Derogatis, L. R. (2000). Brief Symptom Inventory 18: administration, scoring and procedures manual. Minneapolis, MN: NCS Pearson, Inc.

DeRouen, M. C., Smith, A. W., Tao, L., Bellizzi, K. M., Lynch, C. F., Parsons, H. M., ... Keegan, T. H. (2015). Cancer-related information needs and cancer's impact on control over life influence health-related quality of life among adolescents and young adults with cancer. Psychooncology. doi:10.1002/pon.3730

Fletcher, C., Flight, I., Chapman, J., Fennell, K., \& Wilson, C. (2017). The information needs of adult cancer survivors across the cancer continuum: A scoping review. Patient Educ Couns, 100(3), 383-410.

Franke, G. H., Jaeger, S., Glaesmer, H., Barkmann, C., Petrowski, K., \& Braehler, E. (2017). Psychometric analysis of the brief symptom inventory 18 (BSI-18) in a representative German sample. BMC Med Res Methodol, 17(1), 14. doi:10.1186/s12874-016-0283-3

Gatta, G., Zigon, G., Capocaccia, R., Coebergh, J. W., Desandes, E., Kaatsch, P., . . Group, E. W. (2009). Survival of European children and young adults with cancer diagnosed 19952002. Eur J Cancer, 45(6), 992-1005. doi:10.1016/j.ejca.2008.11.042

Gianinazzi, M. E., Essig, S., Rueegg, C. S., von der Weid, N. X., Brazzola, P., Kuehni, C. E., . . Swiss Paediatric Oncology, G. (2014). Information provision and information needs in adult survivors of childhood cancer. Pediatr Blood Cancer, 61(2), 312-318. doi:10.1002/pbc.24762

Gianinazzi, M. E., Rueegg, C. S., Wengenroth, L., Bergstraesser, E., Rischewski, J., Ammann, R. A., . . . for Swiss Pediatric Oncology, G. (2013). Adolescent survivors of childhood cancer: are they vulnerable for psychological distress? Psychooncology, 22(9), 2051-2058. doi:10.1002/pon.3249

Harlan, L. C., Lynch, C. F., Keegan, T. H., Hamilton, A. S., Wu, X. C., Kato, I., . . Group, A. H. S. C. (2011). Recruitment and follow-up of adolescent and young adult cancer survivors: the AYA HOPE Study. J Cancer Surviv, 5(3), 305-314. doi:10.1007/s11764-011-0173-y

Hewitt, M., Greenfield, S., \& Stovall, E. (2006). From Cancer Patient to Cancer Survivor: Lost in Translation. Retrieved from

Husson, O., Mols, F., \& van de Poll-Franse, L. V. (2011). The relation between information provision and health-related quality of life, anxiety and depression among cancer survivors: a systematic review. Ann Oncol, 22(4), 761-772. doi:10.1093/annonc/mdq413

Keegan, T. H., Lichtensztajn, D. Y., Kato, I., Kent, E. E., Wu, X. C., West, M. M., . . Smith, A. W. (2012). Unmet adolescent and young adult cancer survivors information and service needs: a population-based cancer registry study.J Cancer Surviv, 6(3), 239-250. doi:10.1007/s11764-012-0219-9 
Kessels, R. P. (2003). Patients' memory for medical information. J R Soc Med, 96(5), 219-222.

Knijnenburg, S. L., Kremer, L. C., Versluys, A. B., Braam, K. I., Mud, M. S., van der Pal, H. J., . . Jaspers, M. W. (2013). Evaluation of a patient information website for childhood cancer survivors. Support Care Cancer, 21(4), 919-926. doi:10.1007/s00520-012-1604-7

Kuehni, C. E., Rueegg, C. S., Michel, G., Rebholz, C. E., Strippoli, M. P., Niggli, F. K., . . Swiss Paediatric Oncology, G. (2012). Cohort profile: the Swiss childhood cancer survivor study. Int J Epidemiol, 41(6), 1553-1564. doi:10.1093/ije/dyr142

Lack, P. (2016). Ein Pass für das Leben nach dem Krebs - initiiert von Kinderkrebs Schweiz. [Press release]. Retrieved from https://www.kinderkrebsschweiz.ch/portrait/medien/newsroom/newsroom 2016 news 989a596b-b5ac-4f3f8bdc-dcab160edcb6 .html

Lie, H. C. (2017). Mind the Gap: (Unmet) Information needs in cancer care. Patient Educ Couns, 100(3), 381-382. doi:10.1016/j.pec.2017.02.013

Lie, H. C., Loge, J. H., Fossa, S. D., Hamre, H. M., Hess, S. L., Mellblom, A. V., ... Finset, A. (2015). Providing information about late effects after childhood cancer: lymphoma survivors' preferences for what, how and when. Patient Educ Couns, 98(5), 604-611. doi:10.1016/j.pec.2015.01.016

Lin, M., Sansom-Daly, U. M., Wakefield, C. E., McGill, B. C., \& Cohn, R. J. (2017). Health Literacy in Adolescents and Young Adults: Perspectives from Australian Cancer Survivors. J Adolesc Young Adult Oncol, 6(1), 150-158. doi:10.1089/jayao.2016.0024

Mader, L., Vetsch, J., Christen, S., Baenziger, J., Roser, K., Dehler, S., \& Michel, G. (2017). Education, employment and marriage in long-term survivors of teenage and young adult cancer compared with healthy controls. Swiss Med Wkly, 147, w14419. doi:smw.2017.14419

McGuire, L. C. (1996). Remembering what the doctor said: organization and adults' memory for medical information. Exp Aging Res, 22(4), 403-428. doi:10.1080/03610739608254020

Meier, J. H., Ansari, M., Beck Popovic, M., Bergstraesser, E., Brazzola, P., Eisenreich, B., . . Scheinemann, K. (2017). Aftercare in pediatric oncology - current challenges and possible improvements. Paper presented at the 20th Pancare Meeting, Lübeck, Germany.

Oeffinger, K. C., Eshelman, D. A., Tomlinson, G. E., Buchanan, G. R., \& Foster, B. M. (2000). Grading of late effects in young adult survivors of childhood cancer followed in an ambulatory adult setting. Cancer, 88(7), 1687-1695.

Oeffinger, K. C., Mertens, A. C., Sklar, C. A., Kawashima, T., Hudson, M. M., Meadows, A. T., ... Robison, L. L. (2006). Chronic health conditions in adult survivors of childhood cancer. $N$ Engl J Med, 355(15), 1572-1582.

Olsson, M., Jarfelt, M., Pergert, P., \& Enskar, K. (2015). Experiences of teenagers and young adults treated for cancer in Sweden. Eur J Oncol Nurs, 19(5), 575-581. doi:10.1016/j.ejon.2015.03.003

Ormandy, P. (2011). Defining information need in health - assimilating complex theories derived from information science. Health Expect, 14(1), 92-104. doi:10.1111/j.13697625.2010.00598.x

Palmer, S., Mitchell, A., Thompson, K., \& Sexton, M. (2007). Unmet needs among adolescent cancer patients: a pilot study. Palliat Support Care, 5(2), 127-134.

Poplack, D. G., Fordis, M., Landier, W., Bhatia, S., Hudson, M. M., \& Horowitz, M. E. (2014). Childhood cancer survivor care: development of the Passport for Care. Nat Rev Clin Oncol, 11(12), 740-750. doi:10.1038/nrclinonc.2014.175

Pugh, G., Hough, R. E., Gravestock, H. L., Jackson, S. E., \& Fisher, A. (2017). The Health Behavior Information Needs and Preferences of Teenage and Young Adult Cancer Survivors. J Adolesc Young Adult Oncol. doi:10.1089/jayao.2016.0089

Rugbjerg, K., \& Olsen, J. H. (2016). Long-term Risk of Hospitalization for Somatic Diseases in Survivors of Adolescent or Young Adult Cancer. JAMA Oncol, 2(2), 193-200. doi:10.1001/jamaoncol.2015.4393 
Sansom-Daly, U. M., Lin, M., Robertson, E. G., Wakefield, C. E., McGill, B. C., Girgis, A., \& Cohn, R. J. (2016). Health Literacy in Adolescents and Young Adults: An Updated Review. J Adolesc Young Adult Oncol, 5(2), 106-118. doi:10.1089/jayao.2015.0059

Shay, L. A., Parsons, H. M., \& Vernon, S. W. (2017). Survivorship Care Planning and Unmet Information and Service Needs Among Adolescent and Young Adult Cancer Survivors. J Adolesc Young Adult Oncol. doi:10.1089/jayao.2016.0053

Spitzer, C., Hammer, S., Lowe, B., Grabe, H. J., Barnow, S., Rose, M., ... Franke, G. H. (2011). [The short version of the Brief Symptom Inventory (BSI -18): preliminary psychometric properties of the German translation]. Fortschr Neurol Psychiatr, 79(9), 517-523. doi:10.1055/s-0031-1281602

Steliarova-Foucher, E., Stiller, C., Lacour, B., \& Kaatsch, P. (2005). International Classification of Childhood Cancer, third edition. Cancer, 103(7), 1457-1467. doi:10.1002/cncr.20910

Tai, E., Buchanan, N., Townsend, J., Fairley, T., Moore, A., \& Richardson, L. C. (2012). Health status of adolescent and young adult cancer survivors. Cancer, 118(19), 4884-4891. doi:10.1002/cncr.27445

Tonorezos, E. S., \& Oeffinger, K. C. (2011). Research challenges in adolescent and young adult cancer survivor research. Cancer, 117(10 Suppl), 2295-2300. doi:10.1002/cncr.26058

Vetsch, J., Rueegg, C. S., Gianinazzi, M. E., Bergstrasser, E., von der Weid, N. X., \& Michel, G. (2015). Information needs in parents of long-term childhood cancer survivors. Pediatr Blood Cancer, 62(5), 859-866. doi:10.1002/pbc.25418

Ware, J., Jr., Kosinski, M., \& Keller, S. D. (1996). A 12-Item Short-Form Health Survey: construction of scales and preliminary tests of reliability and validity. Med Care, 34(3), 220-233.

Wong, A. W., Chang, T. T., Christopher, K., Lau, S. C., Beaupin, L. K., Love, B., . . Feuerstein, M. (2017). Patterns of unmet needs in adolescent and young adult (AYA) cancer survivors: in their own words. J Cancer Surviv. doi:10.1007/s11764-017-0613-4

Zabora, J., BrintzenhofeSzoc, K., Jacobsen, P., Curbow, B., Piantadosi, S., Hooker, C., ... Derogatis, L. (2001). A new psychosocial screening instrument for use with cancer patients. Psychosomatics, 42(3), 241-246. doi:10.1176/appi.psy.42.3.241

Zebrack, B. (2009). Information and service needs for young adult cancer survivors. Support Care Cancer, 17(4), 349-357. doi:10.1007/s00520-008-0469-2

Zhang, Y., Lorenzi, M. F., Goddard, K., Spinelli, J. J., Gotay, C., \& McBride, M. L. (2014). Late morbidity leading to hospitalization among 5-year survivors of young adult cancer: a report of the childhood, adolescent and young adult cancer survivors research program. Int J Cancer, 134(5), 1174-1182. doi:10.1002/ijc.28453 
TABLE 1. Characteristics of the study population, comparing participants and nonparticipants to the study

\begin{tabular}{llllll}
\hline & $\begin{array}{c}\text { Participants } \\
(\mathbf{N}=160)\end{array}$ & \multicolumn{2}{c}{$\begin{array}{c}\text { Non-Participants }^{\mathrm{a}} \\
(\mathbf{N}=\mathbf{3 0 9})\end{array}$} & \\
\hline $\mathrm{n}$ & $\%^{\mathrm{b}}$ & $\mathrm{n}$ & $\%^{\mathrm{b}}$ & $\mathrm{p}$-value \\
\hline
\end{tabular}

\section{Socio-demographic characteristics}

Sex

Male

Female

Missing

Migration background

No migration background

Migration background

\section{Partnership}

Partner

No partner

\section{Education}

Primary

Secondary

Tertiary

Missing

\section{Employment}

Not employed

Employed

In education

Missing

\section{Clinical characteristics}

\section{Diagnosis}

Leukemia/Lymphoma

Germ cell tumour

73

46

CNS tumour

Other tumour $^{\mathrm{d}}$

\section{Treatment}

Surgery only

Chemotherapy $^{\mathrm{e}}$

Radiotherapy $^{\mathrm{e}}$

Missing

98

62

0

125

35

123

37

13

74

72

1

10

145

4

1
15

26

57

36

41

26
61.3

38.7

0.0

78.1

21.9

76.9

23.1

8.1

46.3

45.0

0.6

10

6.3

n.a.

n.a.

n.a.

n.a.

n.a.

n.a.

n.a.

n.a.

n.a.

68.0

31.0

1.0

\section{$0.110^{\mathrm{C}}$}

n.a.

n.a. n.a.

n.a. n.a.

n.a. n.a.

90.6
4

n.a.

45.6

119

$0.124^{\mathrm{C}}$

38.5

37.9

11.6

9.4

12.0

37

$0.428^{\mathrm{C}}$

35.6

109

35.3

22.5

24.3

25.6

19.4

16.3

60

21.0 


\begin{tabular}{|c|c|c|c|c|c|}
\hline & \multicolumn{2}{|c|}{ Participants } & \multicolumn{2}{|c|}{ Non-Participants $^{\mathrm{a}}$} & \multirow[b]{2}{*}{ p-value } \\
\hline & $\mathrm{n}$ & $\%^{\mathrm{b}}$ & $\mathrm{n}$ & $\%^{\mathrm{b}}$ & \\
\hline \multicolumn{6}{|l|}{ Self-reported relapse } \\
\hline No & 136 & 85.0 & n.a. & n.a. & \\
\hline Yes & 24 & 15.0 & n.a. & n.a. & \\
\hline \multicolumn{6}{|c|}{ Self-reported late-effects } \\
\hline No & 111 & 69.4 & n.a. & n.a. & \\
\hline Yes & 45 & 28.1 & n.a. & n.a. & \\
\hline \multirow[t]{2}{*}{ Missing } & 4 & 2.5 & n.a. & n.a. & \\
\hline & mean & SD & mean & SD & p-value \\
\hline Age at study & 34.0 & 5.8 & 34.2 & 5.6 & $0.754^{f}$ \\
\hline Age at diagnosis & 21.6 & 2.9 & 21.7 & 2.9 & $0.706^{\mathrm{f}}$ \\
\hline Time since diagnosis & 12.4 & 4.8 & 12.5 & 4.8 & $0.884^{\mathrm{f}}$ \\
\hline \multicolumn{6}{|c|}{$\begin{array}{l}\text { Abbreviations: n.a.= not available; CNS = central nervous system; SD=standard deviation } \\
\text { a Non-participants include: AYA survivors who did not respond }(\mathrm{n}=208) \text {, with unknown } \\
\text { address }(\mathrm{n}=80) \text { or who refused to participate }(\mathrm{n}=21) \\
{ }^{\mathrm{b}} \text { Column percentages are given } \\
{ }^{\mathrm{c}} \mathrm{P} \text {-value calculated from Chi-square statistic not including the missings } \\
{ }^{\mathrm{d}} \text { Other: Neuroblastoma, renal tumour, hepatic tumour, bone tumour or soft tissue sarcoma } \\
\text { e Chemotherapy may include surgery; radiotherapy may include chemotherapy and/or surgery } \\
{ }^{\mathrm{f}} \mathrm{P} \text {-value calculated from two sample t-test }\end{array}$} \\
\hline
\end{tabular}


TABLE 2. Factors associated with information needs for each of the four topics disease, treatment, follow-up and late effects (from univariable logistic regression models)

\begin{tabular}{|c|c|c|c|c|c|c|c|c|c|c|c|c|c|c|c|c|c|c|c|c|}
\hline & \multicolumn{5}{|c|}{ Information need: disease } & \multicolumn{5}{|c|}{ Information need: treatment } & \multicolumn{5}{|c|}{ Information need: follow-up } & \multicolumn{5}{|c|}{ Information need: late effects } \\
\hline & $\%^{a}$ & OR & $95 \%$ & $\mathbf{C I}$ & $\begin{array}{c}\text { p- } \\
\text { value }\end{array}$ & $\%^{\mathrm{a}}$ & OR & $95 \%$ & $\mathbf{C I}$ & $\begin{array}{c}\text { p- } \\
\text { value }\end{array}$ & $\%^{a}$ & OR & $95 \%$ & CI & $\begin{array}{c}\text { p- } \\
\text { value }\end{array}$ & $\%^{\mathrm{a}}$ & OR & 95\% & $\mathbf{C I}$ & $\begin{array}{c}\text { p- } \\
\text { value }\end{array}$ \\
\hline & & & & & & & & & & & & & & & & & & & & \\
\hline Male & 59.2 & 1.00 & & & & 56.1 & 1.00 & & & & 71.4 & 1.00 & & & & 77.6 & 1.00 & & & \\
\hline Female & 56.5 & 0.89 & 0.47 & 1.70 & & 54.8 & 0.95 & 0.50 & 1.80 & & 71.0 & 0.98 & 0.48 & 1.97 & & 80.7 & 1.21 & 0.55 & 2.65 & \\
\hline $\begin{array}{l}\text { Education } \\
\text { Secondary education }\end{array}$ & 58.1 & 1.00 & & & 0.647 & 59.5 & 1.00 & & & 0.238 & 73.0 & 1.00 & & & 0.885 & 78.4 & 1.00 & & & 0.294 \\
\hline Primary education & 69.2 & 1.62 & 0.46 & 5.75 & & 69.2 & 1.53 & 0.43 & 5.44 & & 69.2 & 0.83 & 0.23 & 3.01 & & 61.5 & 0.44 & 0.13 & 1.54 & \\
\hline Tertiary education & 55.6 & 0.90 & 0.47 & 1.74 & & 48.6 & 0.64 & 0.34 & 1.24 & & 69.4 & 0.84 & 0.41 & 1.72 & & 81.9 & 1.25 & 0.55 & 2.83 & \\
\hline $\begin{array}{l}\text { Partnership } \\
\text { Partner }\end{array}$ & 59.4 & 1.00 & & & 0.568 & 54.5 & 1.00 & & & 0.591 & 70.7 & 1.00 & & & 0.791 & 76.4 & 1.00 & & & 0.173 \\
\hline No partner & 54.1 & 0.81 & 0.38 & 1.69 & & 59.5 & 1.23 & 0.58 & 2.59 & & 73.0 & 1.12 & 0.49 & 2.54 & & 86.5 & 1.97 & 0.70 & 5.53 & \\
\hline $\begin{array}{l}\text { Migration background } \\
\text { No migration background }\end{array}$ & 55.2 & 1.00 & & & 0.152 & 52.8 & 1.00 & & & 0.170 & 68.8 & 1.00 & & & 0.184 & 79.2 & 1.00 & & & 0.794 \\
\hline Migration background & 68.6 & 1.77 & 0.80 & 3.92 & & 65.7 & 1.71 & 0.78 & 3.74 & & 80.0 & 1.81 & 0.73 & 4.51 & & 77.1 & 0.89 & 0.36 & 2.18 & \\
\hline $\begin{array}{l}\text { Psychological distress }^{\mathrm{b}} \\
\text { Not distressed }\end{array}$ & 53.6 & 1.00 & & & 0.025 & 52.0 & 1.00 & & & 0.078 & 71.2 & 1.00 & & & 0.979 & 76.8 & 1.00 & & & 0.238 \\
\hline Distressed & 74.3 & 2.50 & 1.08 & 5.77 & & 68.6 & 2.01 & 0.91 & 4.46 & & 71.4 & 1.01 & 0.44 & 2.32 & & 85.7 & 1.81 & 0.64 & 5.10 & \\
\hline $\begin{array}{l}\text { HRQoL } \\
\text { MCS }^{\mathrm{C}}\end{array}$ & 56.3 & 0.96 & 0.92 & 0.99 & 0.006 & 53.8 & 0.97 & 0.94 & 1.00 & 0.041 & 69.4 & 0.99 & 0.96 & 1.02 & 0.580 & 76.3 & 0.98 & 0.95 & 1.02 & 0.377 \\
\hline $\mathrm{PCS}^{\mathrm{c}}$ & 56.3 & 1.00 & 0.95 & 1.06 & 0.896 & 53.8 & 0.99 & 0.94 & 1.04 & 0.655 & 69.4 & 0.99 & 0.93 & 1.04 & 0.661 & 76.3 & 0.99 & 0.93 & 1.06 & 0.846 \\
\hline $\begin{array}{l}\text { Diagnosis } \\
\text { Leukemia \& Lymphoma }\end{array}$ & 64.4 & 1.00 & & & 0.363 & 57.5 & 1.00 & & & 0.514 & 75.3 & 1.00 & & & 0.707 & 80.8 & 1.00 & & & 0.325 \\
\hline CNS tumour & 60.0 & 0.83 & 0.27 & 2.59 & & 53.3 & 0.84 & 0.28 & 2.57 & & 73.3 & 0.90 & 0.25 & 3.18 & & 60.0 & 0.36 & 0.11 & 1.17 & \\
\hline Germ cell tumour & 47.8 & 0.51 & 0.24 & 1.07 & & 47.8 & 0.68 & 0.32 & 1.42 & & 67.4 & 0.68 & 0.30 & 1.53 & & 78.3 & 0.85 & 0.34 & 2.12 & \\
\hline Other tumour $^{\mathrm{d}}$ & 57.7 & 0.75 & 0.30 & 1.88 & & 65.4 & 1.39 & 0.55 & 3.54 & & 65.4 & 0.62 & 0.23 & 1.63 & & 84.6 & 1.31 & 0.39 & 4.40 & \\
\hline
\end{tabular}




\begin{tabular}{|c|c|c|c|c|c|c|c|c|c|c|c|c|c|c|c|c|c|c|c|c|}
\hline & \multicolumn{5}{|c|}{ Information need: disease } & \multicolumn{5}{|c|}{ Information need: treatment } & \multicolumn{5}{|c|}{ Information need: follow-up } & \multicolumn{5}{|c|}{ Information need: late effects } \\
\hline & $\%$ & OR & $95 \%$ & CI & $\begin{array}{l}\text { p- } \\
\text { value }\end{array}$ & $\%$ & OR & $95 \%$ & CI & $\begin{array}{l}\text { p- } \\
\text { value }\end{array}$ & $\%$ & OR & $95 \%$ & CI & $\begin{array}{l}\text { p- } \\
\text { value }\end{array}$ & $\%$ & OR & $95 \%$ & $\mathbf{C I}$ & $\begin{array}{l}\text { p- } \\
\text { value }\end{array}$ \\
\hline Treatment & & & & & 0.998 & & & & & 0.663 & & & & & 0.398 & & & & & 0.544 \\
\hline Surgery only & 56.1 & 1.00 & & & & 57.9 & 1.00 & & & & 70.2 & 1.00 & & & & 73.7 & 1.00 & & & \\
\hline Chemotherapy $^{\mathrm{e}}$ & 55.6 & 0.98 & 0.42 & 2.26 & & 55.6 & 0.91 & 0.39 & 2.11 & & 75.0 & 1.28 & 0.50 & 3.28 & & 83.3 & 1.79 & 0.62 & 5.14 & \\
\hline Radiotherapy $^{\mathrm{e}}$ & 56.1 & 1.00 & 0.44 & 2.24 & & 48.8 & 0.69 & 0.31 & 1.55 & & 61.0 & 0.66 & 0.28 & 1.55 & & 78.1 & 1.27 & 0.49 & 3.27 & \\
\hline Relapse & & & & & 0.982 & & & & & 0.772 & & & & & 0.138 & & & & & 0.542 \\
\hline No & 58.1 & 1.00 & & & & 55.2 & 1.00 & & & & 69.1 & 1.00 & & & & 77.9 & 1.00 & & & \\
\hline Yes & 58.3 & 1.01 & 0.42 & 2.44 & & 58.3 & 1.14 & 0.47 & 2.74 & & 83.3 & 2.23 & 0.72 & 6.94 & & 83.3 & 1.42 & 0.45 & 4.46 & \\
\hline Late effects & & & & & 0.929 & & & & & 0.748 & & & & & 0.692 & & & & & 0.319 \\
\hline No & 58.6 & 1.00 & & & & 55.0 & 1.00 & & & & 72.2 & 1.00 & & & & 77.5 & 1.00 & & & \\
\hline Yes & 57.8 & 0.97 & 0.48 & 1.95 & & 57.8 & 1.12 & 0.56 & 2.26 & & 68.9 & 0.86 & 0.40 & 1.83 & & 84.4 & 1.58 & 0.63 & 3.96 & \\
\hline Age at diagnosis (years) & & & & & 0.920 & & & & & 0.733 & & & & & 0.269 & & & & & 0.463 \\
\hline $16-20$ & 58.6 & 1.00 & & & & 57.1 & 1.00 & & & & 75.7 & 1.00 & & & & 81.4 & 1.00 & & & \\
\hline $21-25$ & 57.8 & 0.97 & 0.51 & 1.82 & & 54.4 & 0.90 & 0.48 & 1.68 & & 67.8 & 0.67 & 0.33 & 1.36 & & 76.7 & 0.75 & 0.35 & 1.63 & \\
\hline $\begin{array}{l}\text { Time since diagnosis } \\
\text { (years) }\end{array}$ & & & & & 0.202 & & & & & 0.425 & & & & & 0.271 & & & & & 0.615 \\
\hline $5-10$ & 61.0 & 1.00 & & & & 59.3 & 1.00 & & & & 78.0 & 1.00 & & & & 81.4 & 1.00 & & & \\
\hline $11-15$ & 64.7 & 1.17 & 0.54 & 2.55 & & 58.8 & 0.98 & 0.46 & 2.10 & & 70.6 & 0.68 & 0.29 & 1.60 & & 80.4 & 0.94 & 0.36 & 2.44 & \\
\hline $16+$ & 48.0 & 0.59 & 0.28 & 1.26 & & 48.0 & 0.63 & 0.30 & 1.35 & & 64.0 & 0.50 & 0.22 & 1.17 & & 74.0 & 0.65 & 0.26 & 1.62 & \\
\hline $\begin{array}{l}\text { Note: Statistically sign } \\
\text { related quality of life; } \\
{ }^{\mathrm{a}} \text { Percentage of survivol } \\
{ }^{\mathrm{b}} \text { Measured with the Bri } \\
{ }^{\mathrm{c}} \mathrm{MCS} \text { and PCS are inc } \\
\text { less likely to have info } \\
\text { information needs. } \\
{ }^{\mathrm{d}} \text { Other: Neuroblastoma } \\
{ }^{\mathrm{e}} \text { Chemotherapy may in }\end{array}$ & $\begin{array}{l}\text { ant v } \\
\text { S, m } \\
\mathrm{f} \text { the } \\
\text { Symp } \\
\text { ed in } \\
\text { tion } \\
\text { nal to }\end{array}$ & $\begin{array}{l}\text { alues } \\
\text { ental c } \\
\text { respec } \\
\text { tom I } \\
\text { the m } \\
\text { needs, } \\
\text { dmour }\end{array}$ & $\begin{array}{l}\mathrm{p}<0.0 \\
\text { ompor } \\
\text { tive ca } \\
\text { ivento } \\
\text { del as } \\
\text { where } \\
\text { hepat }\end{array}$ & $\begin{array}{l}\text { ) are } \\
\text { ent st } \\
\text { egor } \\
\text { y-18 } \\
\text { conti } \\
\text { is an } \\
\text { c tum }\end{array}$ & $\begin{array}{l}\text { highl } \\
\text { umma } \\
\text { y who } \\
\text { (BSI- } \\
\text { inuous } \\
\text { OR> }\end{array}$ & $\begin{array}{l}\text { hted } \\
\text { (SF } \\
\text { ndic } \\
\text { 3) } \\
\text { arial } \\
\text { ndic }\end{array}$ & $\begin{array}{l}\text { old. } \\
\text { 12); P } \\
\text { ted to } \\
\text { les. Ar } \\
\text { tes tha } \\
\text { mour }\end{array}$ & $\begin{array}{l}\text { bbre } \\
\mathrm{CS}, \mathrm{pl} \\
\text { have i } \\
\text { OR } \\
\text { t surv }\end{array}$ & $\begin{array}{l}\text { iation } \\
\text { ysical } \\
\text { fform } \\
1 \text { indi } \\
\text { vors } \\
\text { tissue }\end{array}$ & $\begin{array}{l}\text { 1s: OR } \\
\text { l com } \\
\text { lation } \\
\text { icates } \\
\text { with } 1\end{array}$ & $\begin{array}{l}\text { Odds } \\
\text { ment } \\
\text { eeds i } \\
\text { lat su } \\
\text { sher I } \\
\text { la }\end{array}$ & $\begin{array}{l}\text { Ratic } \\
\text { sumn } \\
\text { n the } \\
\text { vivor } \\
\text { ACS/1 }\end{array}$ & $\begin{array}{l}\text { CI, } \\
\text { ary (S } \\
\text { orres) } \\
\text { with } \\
\text { CS (h }\end{array}$ & $\begin{array}{l}\text { nfid } \\
\text {-12); } \\
\text { igdin } \\
\text { ighe } \\
\text { gher }\end{array}$ & $\begin{array}{l}\text { ence I } \\
\text { CNS } \\
\text { ig top } \\
\text { MRQ }\end{array}$ & $\begin{array}{l}\text { erval } \\
\text { Centr } \\
\text { PCS } \\
\text { ) are }\end{array}$ & $\begin{array}{l}\text { HRQ } \\
\text { I Ner } \\
\text { ighe } \\
\text { nore }\end{array}$ & $\begin{array}{l}\text { Lus } \mathrm{He} \\
\text { HRQ } \\
\text { ikely }\end{array}$ & $\begin{array}{l}\text { ystem } \\
\text { ystem } \\
\text { oL) ar } \\
\text { o have }\end{array}$ & \\
\hline
\end{tabular}


FIGURE 1. Perceived information provision on disease, treatment, follow-up and late effects by format of communication (only oral, only written, oral \& written, no information) in adolescent and young adult cancer survivors ( $\mathrm{N}=160$ for each topic).

घ Only oral information $\quad$ Only written information

घ Oral \& written information $\square$ No information

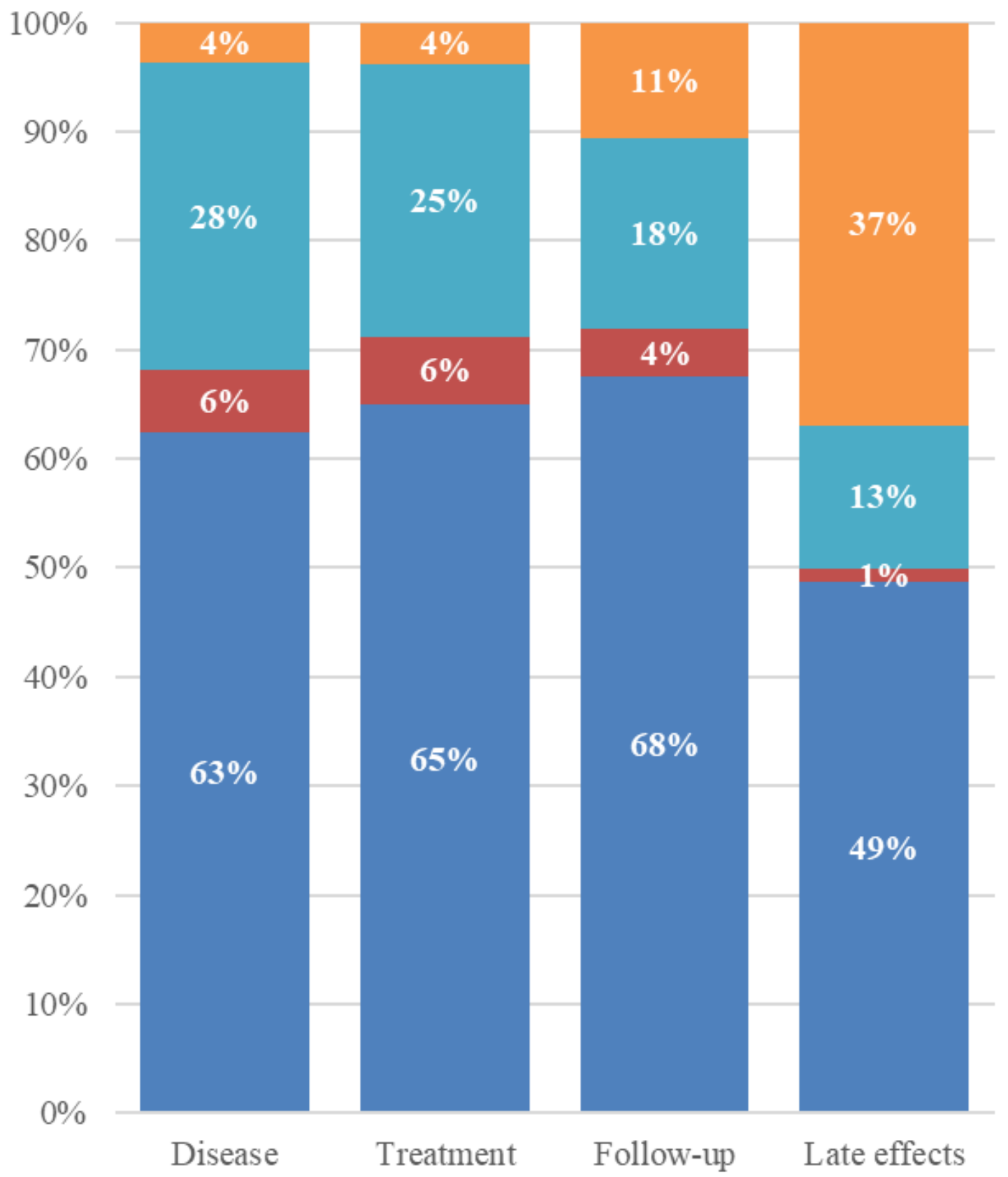


FIGURE 2. Current information needs regarding disease, treatment, follow-up and late effects in adolescent and young adult cancer survivors ( $\mathrm{N}=160$ for each topic).

\section{- Information need $\quad$ No information need}

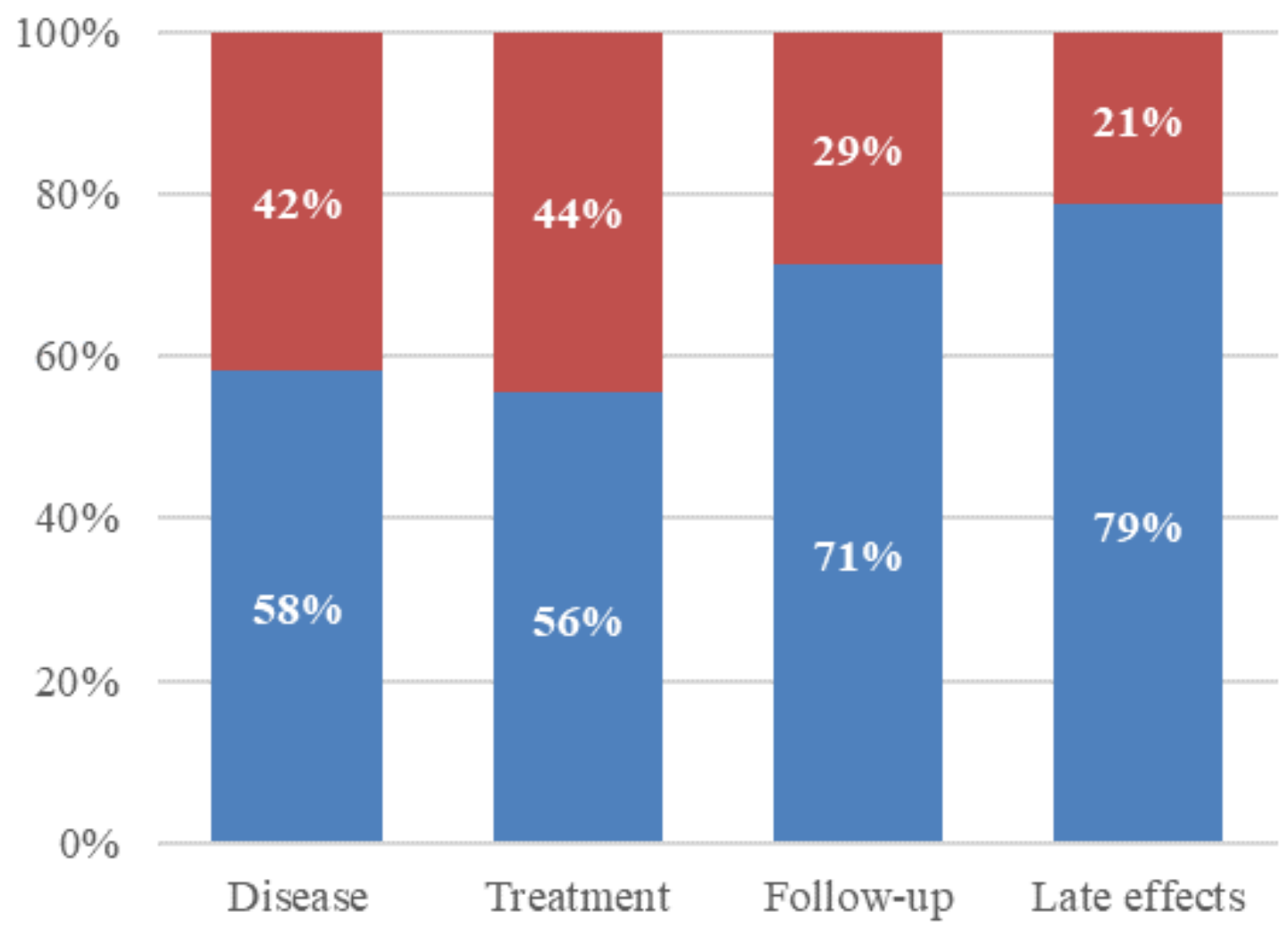


FIGURE 3. Current information needs regarding disease, treatment, follow-up and late effects stratified by format of previously received information (received oral information only, received written information only, received oral and written information, received no information).

Information need in the respective topic $\quad$ No information need in the respective topic

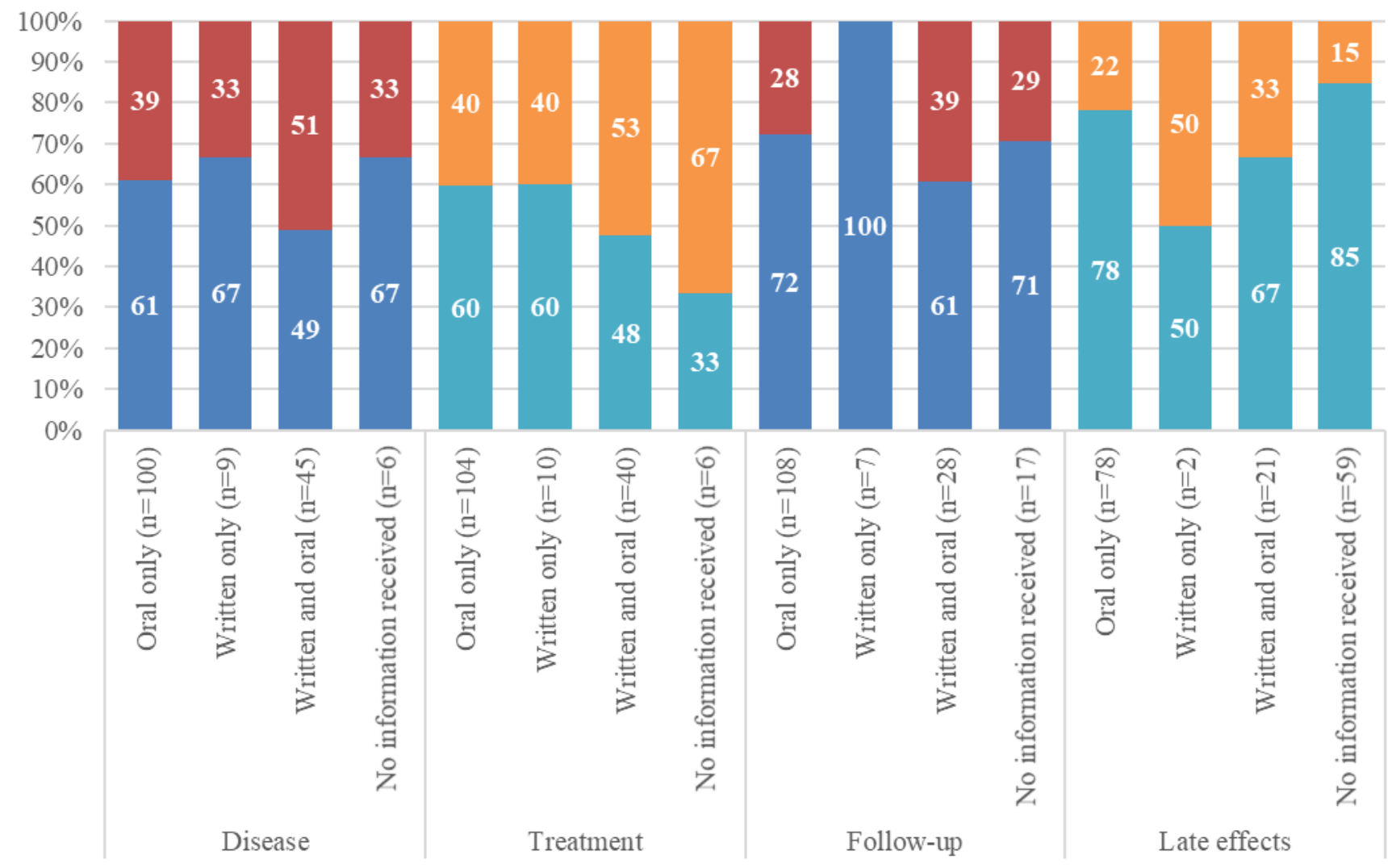


FIGURE 4. Preferred format of communication for information provision regarding disease, treatment, follow-up and late effects in adolescent and young adult cancer survivors with information needs.

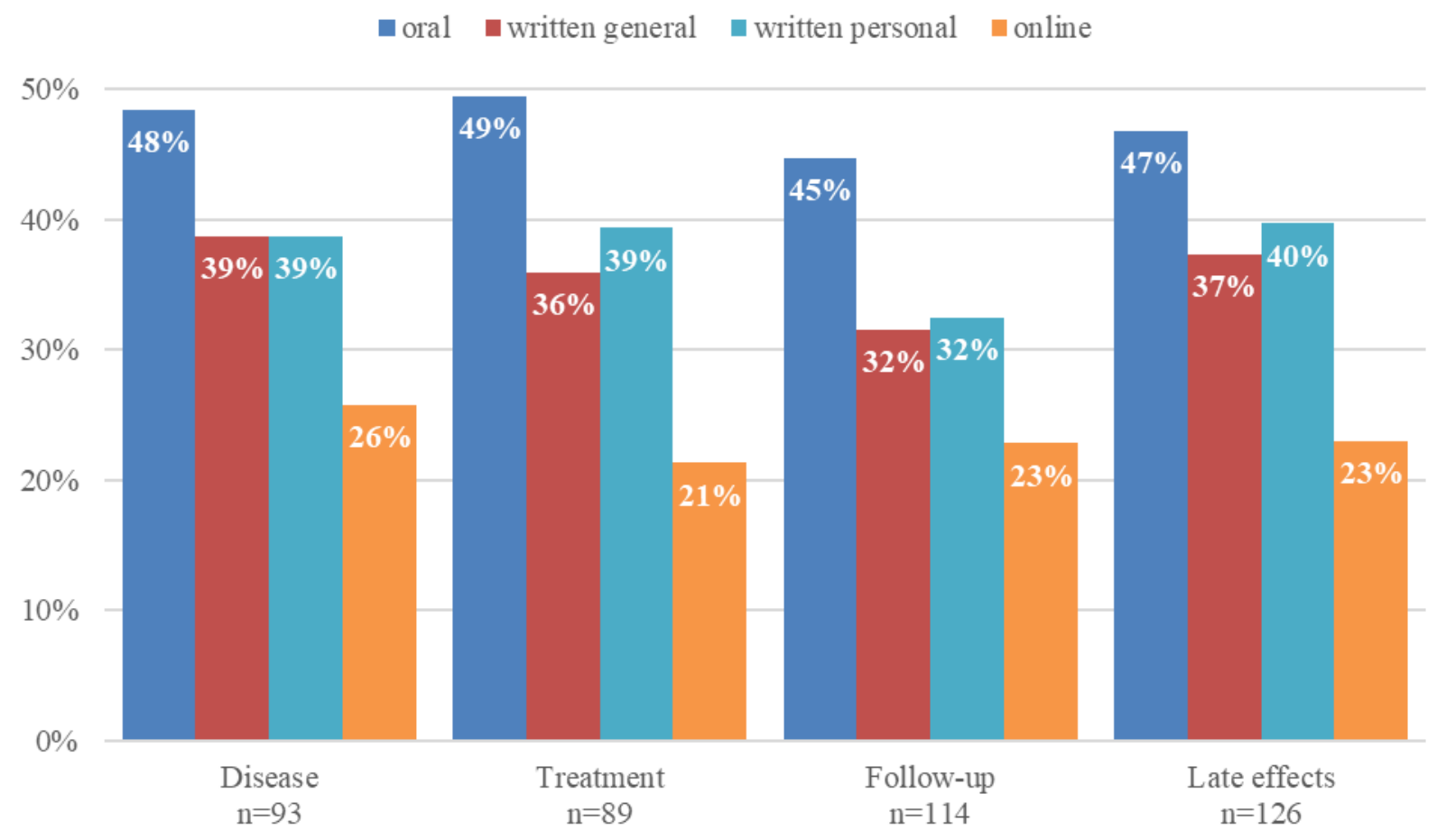

Note: Proportions do not add up to $100 \%$ for each topic, as participants could indicate more than one preferred format of communication. 
SUPPLEMENTAL FIGURE 1 Participants and non-participants of the study

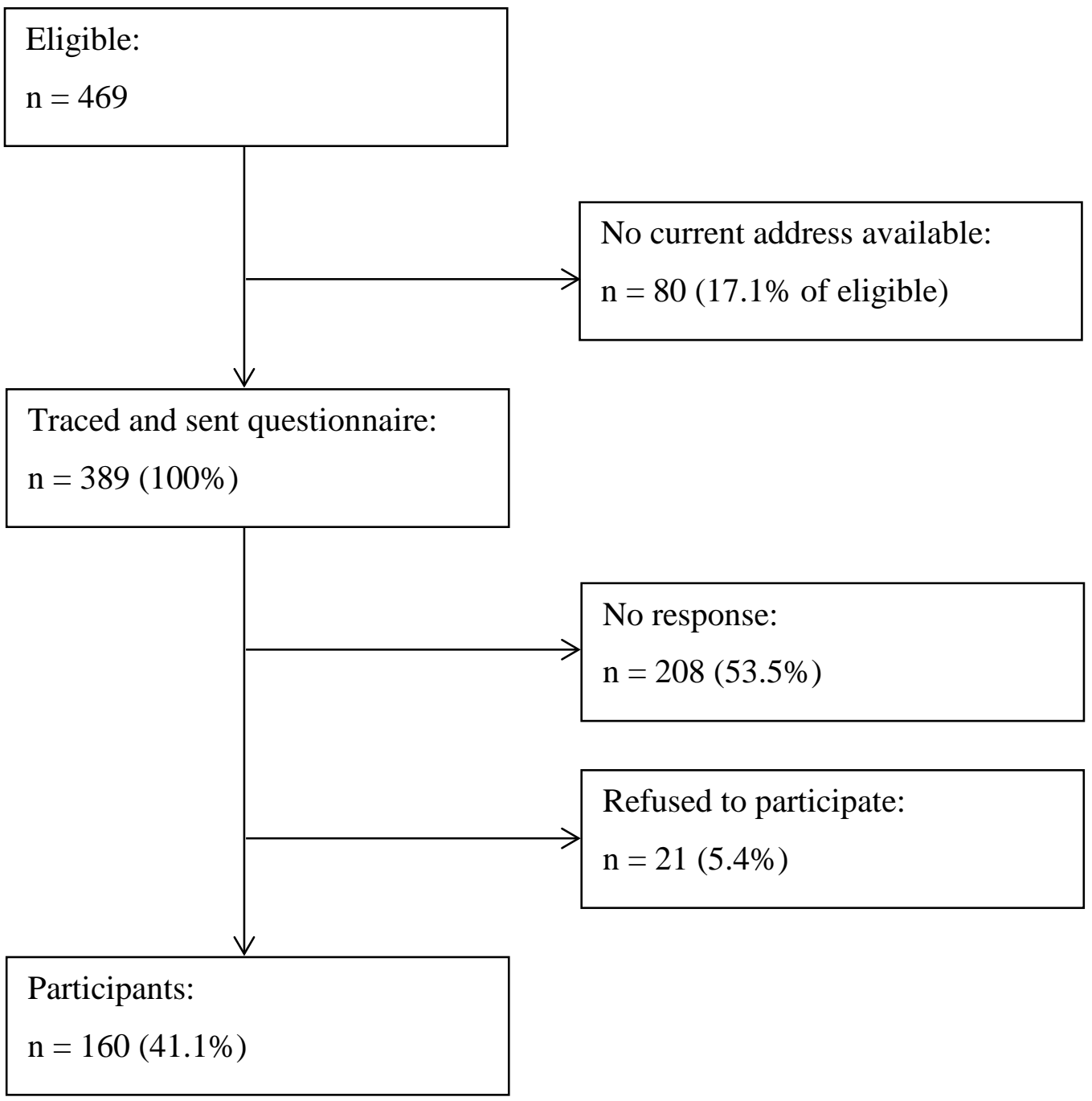

